\title{
A genetic algorithm for a bi-objective mathematical model for dynamic virtual cell formation problem
}

\author{
Mostafa Moradgholi $^{1} \cdot$ Mohammad Mahdi Paydar $^{2} \cdot$ Iraj Mahdavi $^{1} \cdot$ \\ Javid Jouzdani $^{3}$
}

Received: 12 April 2015/Accepted: 29 April 2016/Published online: 10 May 2016

(c) The Author(s) 2016. This article is published with open access at Springerlink.com

\begin{abstract}
Nowadays, with the increasing pressure of the competitive business environment and demand for diverse products, manufacturers are force to seek for solutions that reduce production costs and rise product quality. Cellular manufacturing system (CMS), as a means to this end, has been a point of attraction to both researchers and practitioners. Limitations of cell formation problem (CFP), as one of important topics in CMS, have led to the introduction of virtual CMS (VCMS). This research addresses a bi-objective dynamic virtual cell formation problem (DVCFP) with the objective of finding the optimal formation of cells, considering the material handling costs, fixed machine installation costs and variable production costs of machines and workforce. Furthermore, we consider different skills on different machines in workforce assignment in a multi-period planning horizon. The biobjective model is transformed to a single-objective fuzzy goal programming model and to show its performance; numerical examples are solved using the LINGO software. In addition, genetic algorithm (GA) is customized to tackle large-scale instances of the problems to show the performance of the solution method.
\end{abstract}

Mohammad Mahdi Paydar

paydar@nit.ac.ir

1 Department of Industrial Engineering, Mazandaran University of Science and Technology, Babol, Iran

2 Department of Industrial Engineering, Babol University of Technology, Babol, Iran

3 Department of Industrial Engineering, Najafabad Branch, Islamic Azad University, Najafabad, Iran
Keywords Virtual cell formation · Genetic algorithm • Workforce assignment - Bi-objective mathematical programming · Fuzzy goal programming

\section{Introduction}

In current competitive business environment, customers demand diverse products with higher quality at lower costs. Therefore, manufacturers tend to reduce investment on tools, parts and area and increase their flexibility. With more efficient overall control techniques, companies and businesses use effective approaches in supply, manufacturing and distribution. Production costs constitute a significant share in the total costs incurred by a company. Conventional manufacturing systems (e.g., workshop or flowshop) are not flexible enough to respond to changes. As a result, cellular manufacturing $(\mathrm{CM})$ as technique, stem from group technology (GT) has emerged as a promising manufacturing system. $\mathrm{CM}$ is described as a manufacturing procedure which produces part families within a cell of machines serviced by operators and/or robots functioning only within the cell. CMSs have some advantages, such as reduction in lead times, work-in-process inventories, setup times, etc. (Heragu 1994; Wemmerlov and Hyer 1989). However, the performance of CMS depends significantly on the stability of demand reGArding the volume and mix.

Dynamic cellular manufacturing system (DCMS) is one of the methods proposed for increasing the applicability of CMS when the demand for products fluctuates. In DCMS, to meet the demand in each period, the configuration of cells can be changed from one period to another (Rheault et al. 1995). However, the actual reconfiguration of cells may be time-consuming and costly. Furthermore, if these 
changes occur very frequently with stationary machines, the implementation of these systems is burdensome if not impossible (Thomalla 2000). In VCMS, unlike traditional cellular manufacturing, machines are not physically grouped into cells nor actually moved from their positions. Hence, some costs like assigning machines to cells or relocation of machines are not incurred. In VCMS, better controlling and planning of production is obtained by grouping of machines into virtual cells. VCMSs are capable of responding to demand fluctuations in a reasonable amount of time due to their high flexibility.

When a product mix or part demand level changes from a period to another, the configuration of cells may not be optimal anymore. In other words, the cells are reconfigured in the beginning of a period leading to a change in machine groups and parts families and work teams. Dynamic virtual cell formation (DVCF), unlike conventional dynamic manufacturing systems, can be utilized in this reGArd while reducing some costs, such as actual machine relocation costs. Figure 1 depicts an example of cellular reconfiguration in a dynamic environment. It is supposed that there are nine machines which are stationary for two periods. It can be easily seen that the manufacturing cells are virtual.

\section{Literature review}

DCMS has been a point of attraction to both researchers and practitioners. Slomp et al. (2005) addressed the design of VCMS considering the limited availability of workers and worker skills. They presented a goal programming formulation, in which in the first stage, jobs and machines are grouped, and in the second step, workers are grouped to form a VCMS. Their objective was to assign the available capacity as efficiently as possible and also to make the VCMS as independent as possible. Nomden et al. (2006) reviewed the previous researches in the subject of VCMS.
They addressed several definitions of virtual cells, offered by several researchers, and presented the potential problems for future researches. Mak et al. (2007) proposed a methodology for designing VCMS considering CFP and production scheduling problems. Their methodology included (1) a mathematical model for minimizing the total materials/components travelling distance subject to constraints, such as delivery due dates of products, capacities of resources, and critical tool limitations, and (2) an ant colony optimization method for solving cell formation and production scheduling. Liang et al. (2011) surveyed manufacturing resource modelling methods with a focus on resource element approach. They presented a functionclustering-degree concept addressing the trade-off between the granularity and quantity of virtual cells to verify the reconfiguration of manufacturing systems for solving virtual cell formation problem (VCFP). Mahdavi et al. (2011a) proposed an FGP-based approach to bi-objective mathematical model of CFP and production planning in a DVCMS. The objective of their research was to minimize the exceptional elements (EEs), holding and backorder costs in a cubic space of machine-part-worker incidence matrix. Rezazadeh et al. (2011) presented a mathematical model for DVCFP in which product mix/demand is variant in each period. The assumptions of their model were (1) considering operation sequence for the variety of processes as alternatives, (2) considering machines time capacity, maximum cell size and work capacity for each virtual cell. The objective of their proposed model was finding optimum number of virtual cells to minimize production, material transportation, inventory and manufacturing costs in each period. Nikoofarid and Aalaei (2012) designed a mathematical model for production planning in a dynamic virtual cellular manufacturing (DVCM) considering demand and part mix variation, machine capacity and as machine and worker availability as the main constraints. Han et al. (2014) addressed the problem of virtual cellular multi-period dynamic reconfiguration. They developed a
2

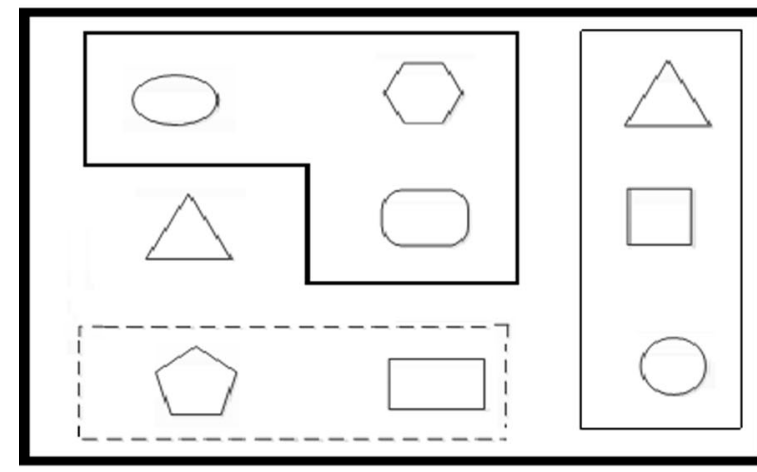

1

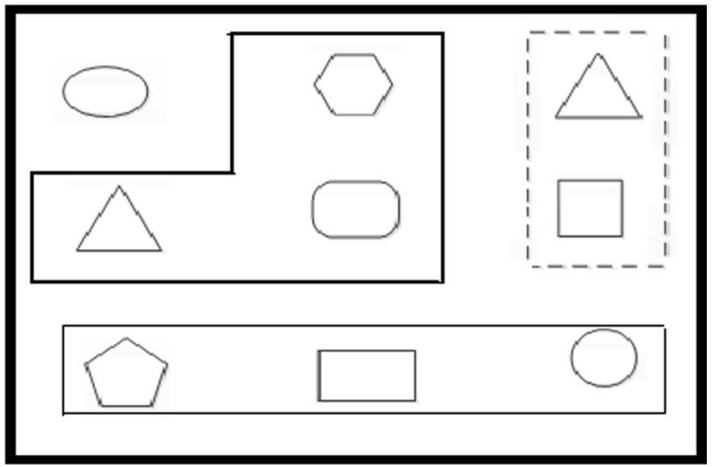

Fig. 1 Reconfiguration of virtual cells in a dynamic environment 
model to incorporate the parameters of the problems, including product dynamic demand, machine capacity, operation sequence, balanced workload, alternative routings and batch setting. The objective of their mixed integer programming model is to minimize the total costs of operation, raw materials movements, inventory holding and process routes setup. Paydar and Saidi-Mehrabad (2015) developed a bi-objective possibilistic optimization mathematical model for formulating the integrated dynamic virtual cell formation and supply chain problem in a multi-echelon, multi-product and multi-period network. They developed a two-stage procedure, in which in the first stage, the proposed model is converted into an equivalent auxiliary crisp model, and in the second stage, a revised multi-choice goal programming approach is used for finding a compromise solution.

Although tremendous amount of research has already been conducted and published around CMS, the literature on DVCMS is still scarce. This paper is concentrated on DVCMS for processing multiple part types using multiple machine types and workers with different skills considering multiple candidate machine locations. We assume that several machines of any machine type are available for parts processing. In addition, we suppose that each worker is able to operate more than one machine in one cell.

In this paper, a DVCMS with several part types assigned to virtual cells to be processed by machines with different potential locations and cross-functional workers in a multi-period planning horizon is studied. In addition, more than one machine of each type may be available for part processing; i.e., duplicate machines are also considered. In this paper, unlike previous researches, we consider virtual cell of workers, machines (with candidate locations) and parts, simultaneously. The cost (number) of transportations between cells, as a major issue in DVCMS, is minimized. Furthermore, the number of exceptional elements is minimized as an objective function of the proposed model. The addressed problem is obviously NP-hard and considering dynamic conditions makes it even harder. Therefore, deterministic approaches may fail to efficiently solve real-world instances of the problem. Hence, metaheuristic approaches should be applied to obtain a satisfying solution in a reasonable amount of time. According to the literature and previously published researches (Mahdavi et al. 2009; Paydar and Saidi-Mehrabad 2013; Bootaki et al. 2014), genetic algorithm (GA) is capable of finding efficient solutions in the cell formation problems, and therefore, this algorithm is utilized for solving the proposed DVCMS mathematical problem. The main contributions of this paper to the literature on DVCMS are as follows:
1. Considering duplicate machines;

2. Simultaneous grouping of workers, machines and parts into virtual cells;

3. Proposing a bi-objective model that optimizes both:

(a) The exceptional and void elements, and;

(b) The total cost consisted of the fixed setup costs, the variable machine operation costs and the worker salary costs;

4. Developing a GA algorithm as a solution approach to the proposed model.

\section{Problem description and formulation}

In this section, the proposed mathematical model is formulated using a 4D machine-part-worker-location incidence matrix.

\section{Sets}

$i \quad$ index for part type $(i=1,2 \ldots, P)$;

$m$ index for machine type $(m=1,2 \ldots, M)$;

$w$ index for worker type $(w=1,2, \ldots, W)$;

$k \quad$ index for cell $(k=1,2, \ldots, C)$;

$l \quad$ index for location $(l=1,2, \ldots, L)$;

$t \quad$ index for time period $(t=1,2, \ldots, T)$.

\section{Input parameters}

$r_{m w} \quad 1$ if worker type $w$ is capable of operating machine type $m$ and 0 otherwise;

$a_{i m} \quad 1$ if part type $i$ can be processed on machine type $m$ and 0 otherwise;

$\mathrm{RW}_{w t}$ available time for worker $w$ in period $t$;

$\mathrm{RM}_{m t}$ available time for machine $m$ in period $t$;

$t_{i m w} \quad$ processing time of part $i$ on machine type $m$ with worker type $w$;

$D_{i t} \quad$ demand of part $i$ in period $t$;

$\mathrm{SW}_{w t} \quad$ salary cost of worker type $w$ in period $t$;

$C_{m} \quad$ fixed investment cost of machine type $m$;

$\alpha_{m} \quad$ variable cost of machine type $m$.

\section{Decision variables}

$X_{\text {imwklt }} \quad 1$ if part type $i$ is to be processed on machine type $m$ in location $l$ with worker type $w$ in cell $k$ in period $t$ and 0 otherwise;

$\mathrm{NW}_{w k t} \quad$ number of workers of type $w$ allotted to cell $k$ in period $t$; 
$Y_{m l} \quad$ lif machine $m$ is located in location $l$ and 0 otherwise;

$F_{l k t} \quad 1$ if location $l$ is assigned to cell $k$ in period $t$ and 0 otherwise;

$Z_{i k t} \quad 1$ if part $i$ is processed in cell $k$ in period $t$ and 0 otherwise;

$W_{w k t} \quad 1$ if worker type $w$ assigned to cell $k$ in period $t$ and 0 otherwise.

\section{Mathematical model}

$\operatorname{Min} Z_{1}$

$$
\begin{aligned}
= & \sum_{t=1}^{T} \sum_{k=1}^{C} \sum_{l=1}^{L}\left(\sum_{i=1}^{P} \sum_{m=1}^{M} \sum_{w=1}^{W} Y_{m l} \times F_{l k t} \times Z_{i k t} \times W_{w k t}\right. \\
& \left.-\sum_{i=1}^{P} \sum_{m=1}^{M} \sum_{w=1}^{W} Y_{m l} \times F_{l k t} \times Z_{i k t} \times W_{w k t} \times a_{i m} \times r_{m w}\right) \\
& +\sum_{t=1}^{T} \sum_{i=1}^{P} \sum_{m=1}^{M} \sum_{l=1}^{L} \sum_{k=1}^{C} \sum_{w=1}^{W} a_{i m} \\
& \times r_{m w}\left(1-Y_{m l} \times F_{l k t} \times Z_{i k t} \times W_{w k t}\right) .
\end{aligned}
$$

$\operatorname{Min} Z_{2}$

$$
\begin{aligned}
= & \sum_{m=1}^{M} \sum_{l=1}^{L} C_{m} \times Y_{m l} \\
& +\sum_{t=1}^{T} \sum_{k=1}^{C} \sum_{m=1}^{M} \alpha_{m} \times D_{i t} \times t_{i m w} \times X_{i m w k l t} \\
& +\sum_{t=1}^{T} \sum_{k=1}^{C} \sum_{w=1}^{W} \mathrm{SW}_{w t} \times \mathrm{NW}_{w k t} .
\end{aligned}
$$

Subject to

$$
\begin{aligned}
& X_{i m w k l t} \leq Y_{m l} \quad \forall i, m, w, k, l, t . \\
& X_{i m w k l t} \leq F_{l k t} \quad \forall i, m, w, k, l, t . \\
& X_{i m w k l t} \leq W_{w k t} \quad \forall i, m, w, k, l, t . \\
& X_{i m w k l t} \leq Z_{i k t} \quad \forall i, m, w, k, l, t . \\
& \sum_{m=1}^{M} Y_{m l} \leq 1 \quad \forall l . \\
& \sum_{k=1}^{C} F_{l k t}=1 \quad \forall l, t . \\
& \sum_{k=1}^{C} Z_{i k t}=1 \quad \forall i, t . \\
& \mathrm{NW}_{w k t} \leq A \times W_{w k t} \quad \forall k, w, t .
\end{aligned}
$$

$$
\begin{aligned}
& \sum_{i=1}^{P} \sum_{m=1}^{M} \sum_{l=1}^{L} D_{i t} \times t_{i m w} \times X_{i m w k l t} \leq \mathrm{NW}_{w k t} \times \mathrm{RW}_{w t} \\
& \quad \forall w, k, t . \\
& \sum_{i=1}^{P} \sum_{w=1}^{W} D_{i t} \times t_{i m w} \times X_{i m w k l t} \leq Y_{m l} \times \mathrm{RM}_{m t} \quad \forall m, l, k, t .
\end{aligned}
$$

$\sum_{k=1}^{C} \sum_{w=1}^{W} \sum_{l=1}^{L} X_{i m w k l t}=a_{i m} \quad \forall i, m, t$.

$\sum_{k=1}^{K} X_{i m w k l t} \leq a_{i m} \times r_{m w} \quad \forall i, m, w, l, t$.

$Y_{m l} \in\{0,1\} \quad \forall m, l$.

$F_{l k t} \in\{0,1\} \quad \forall l, k, t$.

$W_{w k t} \in\{0,1\} \quad \forall w, k, t$.

$Z_{i k t} \in\{0,1\} \quad \forall i, k, t$.

$X_{\text {imwklt }} \in\{0,1\} \quad \forall i, m, w, l, k, t$.

$\mathrm{NW}_{w k t} \geq 0$ and integer $\forall w, k, t$.

The model has two objectives: in the first objective in (1-1), the goal is minimizing the number of exceptional elements, and in (1-2), the goal is to minimize the total number of voids; in the second objective, in (2-1), we minimize the fixed cost associated with machine investment and installation, and in (2-2), the variable cost of machines is minimized and (2-3) is to minimize the workers' salary cost.

Constraint (3) ensures that if machine $m$ is not assigned to location $l$, then certainly $X_{\text {imwklt }}$ equals zero. Constraint (4) is to ensure that if location $l$ is not assigned to cell $k$ in period $t$, then certainly $X_{\text {imwklt }}$ is equal to zero. Constraint (5) guarantees that if worker type $w$ is not assigned to cell $k$ in period $t$, then certainly $X_{\text {imwklt }}$ is zero. Constraint (6) is for ensuring that if part type $i$ is not assigned to cell $k$ in period $t$, then certainly $X_{\text {imwklt }}$ equals zero. Obviously, only one machine can be location in each location $l$. This is considered by Constraint (7). Each location $l$ should be assigned to one cell $k$ in each period; this fact is modeled by Constraint (8). Constraint (9) ensures that each part $i$ is assigned to only one location $l$ in each cell in the $t$ th period. Constraint (10) determines the number of workers type $w$ in all cells type $k$ in the $t$ th period where $A$ is a large positive number.

Constraint (11) ensures that the sum of assigned time for workforce should not be more than available time. It is noticeable in this constraint that operations are performed only in cells to which the corresponding workers are assigned. This is because if $\mathrm{NW}_{w k t}=0$, then no 
operations in that cell with worker type $w$ can be performed and the left side of the constraint is equal to zero. Obviously, total assigned time to the machine $m$ in the cell $k$ in any period should not exceed the available time for machine $m$ in cell $k$ in each period. This fact is modeled by Constraint (12). Constraint (13) guarantees that each part is assigned to be processed on a machine in a period $t$ with a worker $w$ at a location $l$ and in a cell $k$. Constraint (14) expresses the fact that each part could be manufactured in only one cell and by only one worker. Constraints (15)-(20) specify the allowed intervals and types of decision variables.

\section{Linearization of the proposed model}

The proposed model is obviously non-linear in the first part and the second part of the first objective function. Fortunately, most of the software have the ability to solve complex non-linear models; however, experiences show that solving such problems is usually time-consuming and results in local optima. Therefore, a linear model is practically more preferable and more convenient and efficient to solve. In addition, solving the model in small sizes utilizing fuzzy goal programming that the genetic algorithm method may be used for model verification. To linearize the model, some auxiliary variables and constraints are required to be defined and added to the original model. To linearize Eqs. (1-1) and (1-2), an auxiliary variable, $Q_{\text {imwklt }}$, is introduced as follows:

$Q_{i m w k l t}=Y_{m l} \times F_{l k t} \times Z_{i k t} \times W_{w k t}$.

Regarding $Q_{i m w k l t}$, the following constraints are also added to the model. It is easy to check that depending on the values of the binary variables, $Y_{m l}, F_{l k t}, Z_{i k t}$ and $W_{w k t}$, the defined auxiliary variable, $Q_{i m w k l t}$, acts as the multiplication of the four binary variables.

$$
\begin{aligned}
& Q_{i m w k l t}-Y_{m l}-F_{l k t}-Z_{i k t}-W_{w k t}+3.5 \geq 0 \\
& \quad \forall i, m, w, l, k, t . \\
& \\
& \quad \begin{array}{l}
3.5 \times Q_{i m w k l t}-Y_{m l}-F_{l k t}-Z_{i k t}-W_{w k t} \leq 0 \\
\quad \forall i, m, w, l, k, t .
\end{array}
\end{aligned}
$$

$Q_{i m w k l t} \in\{0,1\} \quad \forall i, m, w, l, k, t$.

\section{Fuzzy goal programming-based approach}

One of the most important differences between one-objective and multi-objective optimization is multi-objective optimization can solve multi-dimensional objective problems. One of the famous methods for solving multiobjective problems is goal programming (GP). However, the application of GP in real-world problems may face two important difficulties: the first is the mathematical expression of the decision maker's imprecise aspiration levels for the goals and the second is the need to optimize all goals simultaneously. Fuzzy goal programming (FGP) is a mathematical decision-making mechanism to incorporate uncertainty and imprecision into the formulation. In practice, a high degree of fuzziness and uncertainty is included in the data set (Mahdavi et al. 2011b). The FGP has been tackled through different methods, such as probability distribution, penalty function, fuzzy numbers, preemptive FGP, interpolated membership function and the weighted additive model. Zimmermann first proposed fuzzy programming for solving the multi-objective linear programming problems (Zimmermann 1978). A number of researchers have extended the fuzzy set theory to the field of goal programming proposed by Narasimhan (1980). The fuzzy model of a generalized multi-objective multi-constrained optimization problem (Yang et al. 1991) can be expressed in what follows. Consider a problem with the following minimization objectives:

$Z_{l}(X) \leq g_{l} \quad l=1,2, \ldots, b$

and subject to constraints:

$d_{j}(X) \leq D_{j} \quad j=1,2, \ldots, m$,

where $l$ is the index of goals, $b$ represents the number of fuzzy-minimum goal constraints, $g_{l}$ is the goal value (target value) for objective $l$ given by the decision maker (DM), $X$ is a $k$-dimensional decision vector, goal constraints are represented by $Z_{l}(X)$ and finally, $G=\left\{X \mid d_{j}(x) \leq D_{j}, j=\right.$ $1, \ldots, m\}$ is the set of system constraints and defines the 
feasible space in which $m$ represents the number of system constraints.

Let $p_{l}$ denote the maximum tolerance limit for $g_{l}$ determined by the DM. Thus, using the concept of fuzzy sets, the membership function of the objective functions can be defined as follows (Zimmermann 1978):

$\left\{\mu_{Z_{l}}(X)= \begin{cases}1 & \text { if } Z_{l}(X)<g_{l} \\ 1-\frac{Z_{l}(X)-g_{l}}{p_{l}} & \text { if } g_{l} \leq Z_{l}(X) \leq g_{l}+p_{l} \\ 0 & \text { if } Z_{l}(X)>g_{l}+p_{l}\end{cases}\right.$

The term $\mu_{z l}(\mathrm{x})$ indicates the desirability of solution $X$ in terms of the objective $l$. The corresponding graph of Eq. (26) is shown in Fig. 2.

The $\alpha$-level sets $Z_{l}^{\lambda}, \quad \forall l \in\{1,2, \ldots, b\}, \quad \forall \lambda \in[0,1]$ are defined as:

$Z_{l}^{\lambda}=\left\{X \mid \mu_{Z_{l}}(X) \geq \lambda, 0 \leq \lambda \leq 1\right\}, \quad l=1,2, \ldots . b$.

Then, the decision space is defined by intersecting the system constraints with the intersection of $\lambda$-level sets as follows:

$Z^{*}=\left\{\bigcap_{l=1}^{b} Z_{l}^{\lambda}\right\} \bigcap G, \quad 0 \leq \lambda \leq 1$.

According to the extension principle, the membership function of $Z$ is defined as follows:

$\mu_{Z}(X)=\min _{l=1,2, \ldots m}\left\{\mu_{Z_{l}}(X)\right\}$.

Finally, the optimal solution, $Z^{*} X^{*}$, must maximize $\mu_{Z}(X)$ by solving the following mathematical programming.

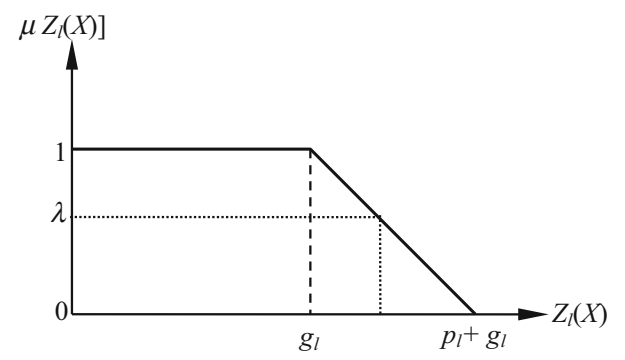

Fig. 2 Membership function related to objectives

\begin{tabular}{|l|l|l|l|l|l|}
\hline 2 & 1 & 4 & 1 & 3 & 3 \\
\hline
\end{tabular}

Fig. 3 Example of chromosome $Y_{m i}$

\begin{tabular}{|l|l|l|l|}
\hline 1 & 3 & 2 & 1 \\
\hline 2 & 2 & 1 & 3 \\
\hline 2 & 1 & 3 & 2 \\
\hline 3 & 1 & 3 & 1 \\
\hline
\end{tabular}

Fig. 4 Chromosome demonstration for variable $Z_{i k t}$

\begin{tabular}{|l|l|l|l|}
\hline 2 & 3 & 2 & 1 \\
\hline 3 & 2 & 1 & 3 \\
\hline 2 & 1 & 3 & 2 \\
\hline 3 & 1 & 3 & 1 \\
\hline
\end{tabular}

Fig. 5 Chromosome representation for variable $F_{l k t}$

\begin{tabular}{|l|l|l|l|}
\hline 3 & 3 & 2 & 1 \\
\hline 2 & 2 & 1 & 3 \\
\hline 2 & 1 & 3 & 2 \\
\hline 3 & 1 & 3 & 1 \\
\hline 1 & 3 & 1 & 2 \\
\hline 2 & 1 & 1 & 1 \\
\hline
\end{tabular}

Fig. 6 Chromosome representation for variable $w_{w k t}$

$$
\begin{aligned}
& \operatorname{Max} Z^{*}=\lambda \\
& \text { s.t. } \\
& \lambda \leq \mu_{Z_{l}}(X), \quad l=1,2, \ldots, b \\
& d_{j}(X) \leq D_{j}, \quad j=1,2, \ldots, m \\
& 0 \leq \lambda \leq 1
\end{aligned}
$$

\section{The GA approach}

GA is inspired by Darwin's theory of evolution and genetic knowledge and is based on elitism. It simulates the genetic evolution of orGAnisms, and its generic usage is as an optimization method. The excellent books by Davis (1991) and Goldberg (1989) described many possible variants of GAs. GA is based on an analogy to the phenomenon of natural selection in biology. First, a chromosome structure is defined to represent the solutions to the problem. An initial solution population is generated either randomly or using a heuristic. Each chromosome is then improved through a selection/elitism mechanism. More specifically, members of the population are selected based on an evaluation function, called "fitness", which associates a value to each member according to its objective function. The higher a member's fitness value, the more likely it is to be selected. Thus, the less fit individuals are replaced by those with higher value. Genetic operators are then applied to the selected members to produce a new generation. This 


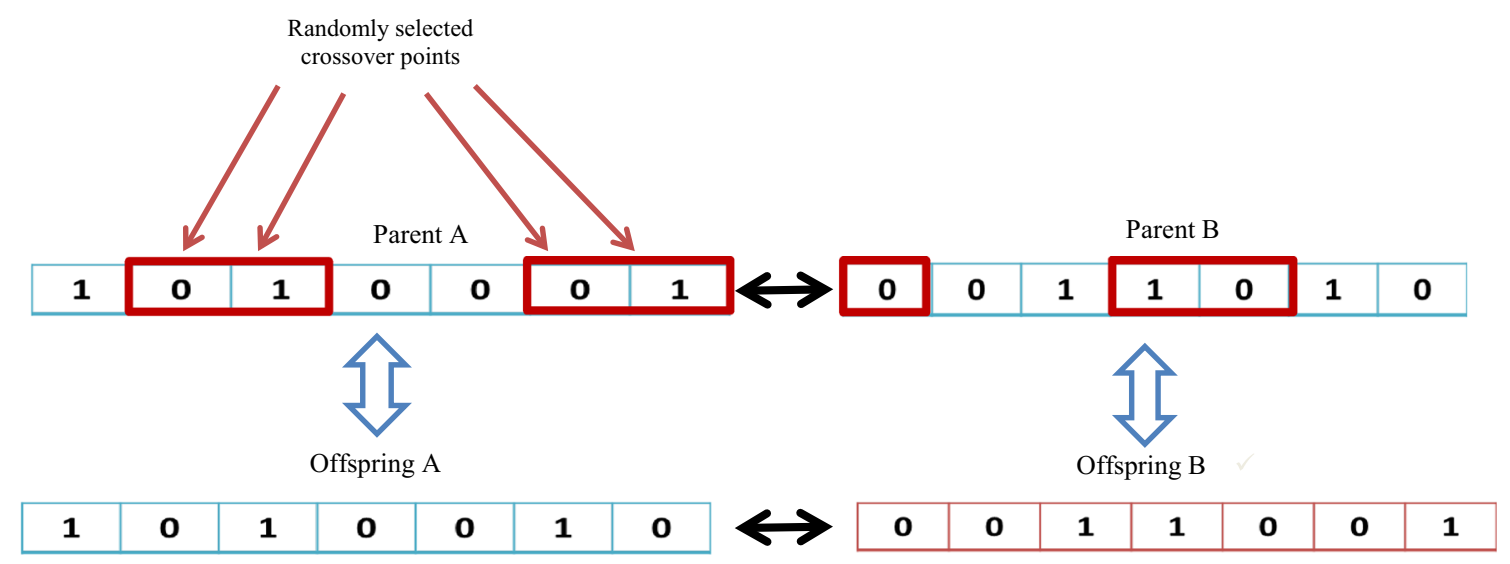

Fig. 7 Uniform crossover

Fig. 8 Proposed mutation

Before mutation

After mutation

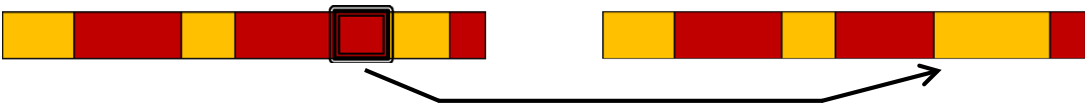

process is repeated until some stopping criteria are reached (Mahdavi et al. 2009). The main components of GA for implementation are:

1. The scheme for coding.

2. The initial population.

3. Adaptation function for evaluating the fitness of each member of the population.

4. Selection procedure.

5. The genetic operators used for combining the solution features for producing a new generation.

6. Certain control parameter values (e.g., population size, number of iterations, genetic operator probabilities, etc.).

\section{The scheme for coding}

For any implementation of GA, the first stage is to map solution characteristics into the format of a chromosome string. Each chromosome is made up of a sequence of genes from a certain alphabet. The alphabet can be a set of binary numbers, real numbers, integers, symbols, or matrices Goldberg (1989).

In genetic algorithms, each chromosome represents a feasible solution in the search space and is formed by a fixed number of genes. Usually, genes are represented using binary codes. In this paper, a four-component chromosome is used for solution representation.

The first component of the chromosome, formed according to the decision variable $Y_{m l}$, is a row vector in which the number of column represents the location and the value within
Table 1 Operation process times in example 1

\begin{tabular}{|c|c|c|c|c|c|c|c|c|c|}
\hline & \multicolumn{3}{|c|}{ Part 1} & \multicolumn{3}{|c|}{ Part 2} & \multicolumn{3}{|c|}{ Part 3} \\
\hline & $\mathrm{W} 1$ & W2 & W3 & W1 & W2 & W3 & W1 & W2 & W3 \\
\hline M1 & 0.3 & 0 & 0 & 0 & 0 & 0 & 0 & 0.3 & 0.3 \\
\hline M2 & 0 & 0 & 0 & 0.2 & 0.4 & 0 & 0 & 0 & 0 \\
\hline M3 & 0 & 0.4 & 0.2 & 0 & 0.3 & 0.1 & 0 & 0 & 0 \\
\hline
\end{tabular}

the column determines the type of machine. For example, in Fig. 3, the first element of the vector is 2 meaning that a machine of type 2 is in located in the location 1.

The next component models the variable, $Z_{i k t}$, and is a matrix with $P$ rows and $T$ columns. The element in row $p$ and column $t$ of the matrix shows the number of the cell in which part $p$ is processed in period $t$. For instance, in Fig. 4, the matrix with four rows and four columns determines the cell numbers for four parts in four periods. The number 3 in the first row and second column means that part number 1 in period 2 is processed in cell 3 .

The variables $F_{l k t}$ and $w_{w k t}$ are represented using a similar matrix utilized to code the variable $Z_{i k t}$. The only difference is that rows in the matrices for $F_{l k t}$ and $w_{w k t}$ represent locations and workers, respectively. Figure 5 illustrates an example of the matrix for $F_{l k t}$ with the element in the first row and the second column being equal to 3 ; showing that location 1 in period 2 is assigned to the cell number 2. Similarly, in Fig. 6, the matrix for variable $w_{w k t}$ is formed by six workforces and four periods. The element in the first row and the first column specifics that worker 1 in period 1 is assigned to the cell 3 . 
Table 2 Machines available times, machines fixed costs and machines variable costs in example 1

Table 3 Machines available times, workers hiring and number of available workers in example 1

\begin{tabular}{lrrr}
\hline & M1 & M2 & M3 \\
\hline RM & 70 & 70 & 70 \\
$C$ & 500 & 400 & 350 \\
$\alpha$ & 20 & 30 & 25 \\
\hline
\end{tabular}

\begin{tabular}{lrrr}
\hline & W1 & W2 & W3 \\
\hline RW & 60 & 60 & 60 \\
SW & 400 & 500 & 450 \\
AW & 4 & 4 & 4
\end{tabular}

\section{The initial population}

Another aspect of GA implementation is generating a set of initial solutions known as the initial population. The number of initial solutions to be included in the population is called population size. The population size is a key factor
Table 5 Output information related to assign each machine to the locations using LINGO in example 1

\begin{tabular}{ccccc}
\hline & L1 & L2 & L3 & L4 \\
\hline M1 & 0 & 0 & 1 & 1 \\
M2 & 1 & 0 & 0 & 0 \\
M3 & 0 & 1 & 0 & 0 \\
\hline
\end{tabular}

in a successful GA implementation. A small population size increases the speed of the algorithm; however, it may prevent the algorithm from converging to satisfying solutions. On the other hand, although a large population usually results in better solutions, it may significantly increase CPU time (Back et al. 1997)

\section{Fitness function}

In GA implementation, a fitness function is used to evaluate the chromosomes for reproduction. The purpose of the fitness function is to measure the quality of the candidate solutions in the population with respect to the objective and constraint functions of the model. The fitness function is

Table 4 Output information of the proposed model related to assign machines and workers to each cell in each period using LINGO in example 1

\begin{tabular}{|c|c|c|c|c|c|c|c|c|c|c|c|c|}
\hline & \multicolumn{3}{|c|}{ Parts assigned to } & \multicolumn{3}{|c|}{ Machines in } & \multicolumn{3}{|c|}{ Worker assigned to } & \multicolumn{3}{|c|}{ Location assigned to } \\
\hline & Cell 1 & Cell 2 & Cell 3 & Cell 1 & Cell 2 & Cell 3 & Cell 1 & Cell 2 & Cell 3 & Cell 1 & Cell 2 & Cell 3 \\
\hline Period 1 & 3 & - & 1,2 & 1 & - & $1,3,2$, & 1 & - & 1,3 & 3 & - & $4,2,1$ \\
\hline Period 2 & 3 & - & 1,2 & 1 & - & $1,3,2$, & 1 & - & 1,3 & 4 & - & $3,2,1$ \\
\hline
\end{tabular}

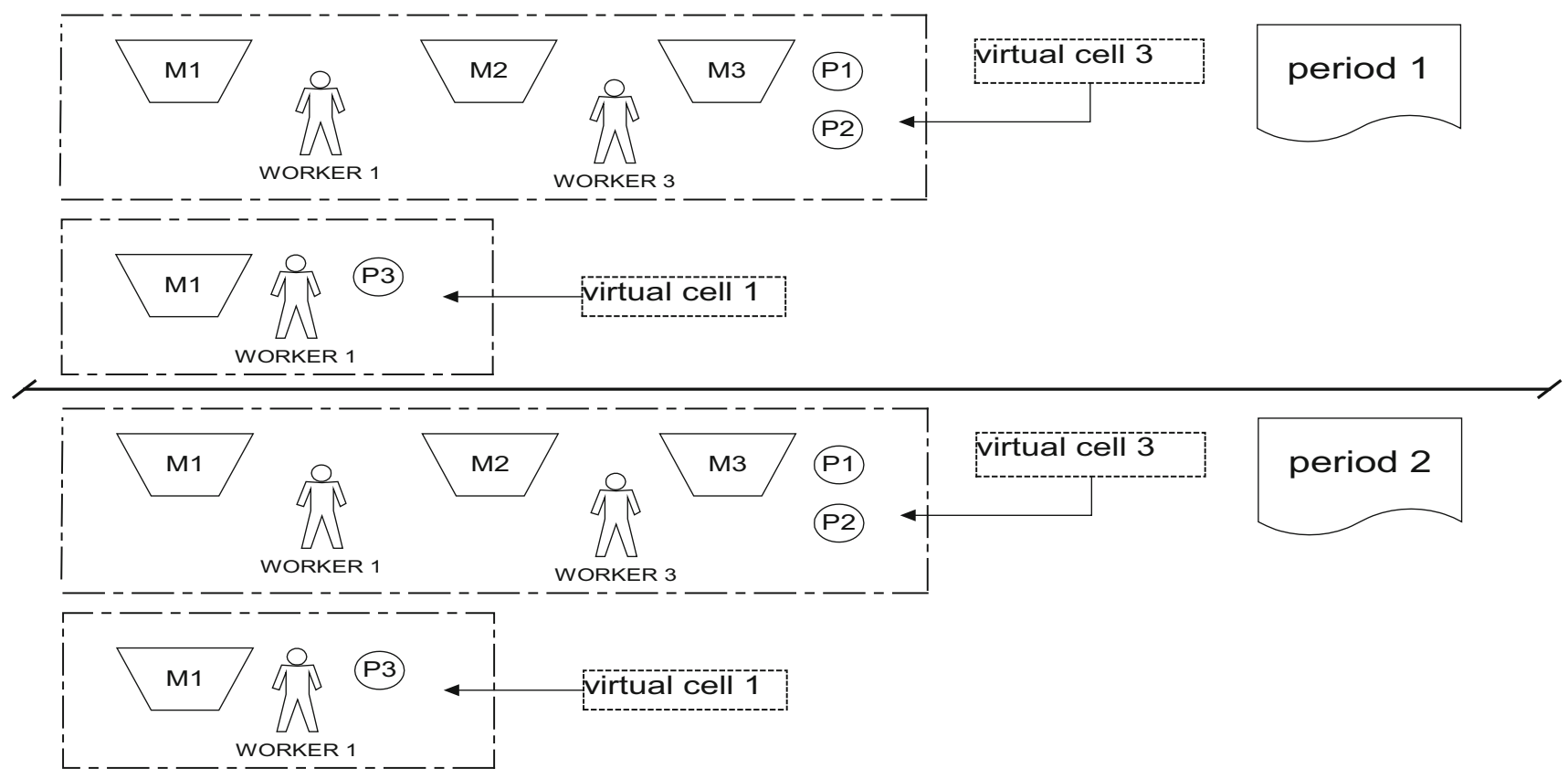

Fig. 9 Cell reconfiguration schema in each period for example 1 
Table 6 Obtained values for FGP variables

\begin{tabular}{llll}
\hline Variable & $\lambda$ & $Z_{1}$ & $Z_{2}$ \\
\hline Value & 0.812501 & 198 & 161,400 \\
\hline
\end{tabular}

calculated according to Eq. (27), where $\lambda$ is the same $*$, and a penalty function is used in fitness function $\left(Z_{X}^{*}\right)$ to satisfy the constraints.

$Z_{X}^{*}=\min \left(\frac{Z^{*}}{1+\text { penalty function }}\right)$.

\section{Selection rule}

The roulette wheel selection procedure, as proposed by Goldberg (1989), is the selection strategy used in the proposed algorithm. The goal of the selection strategy is to allow the "fittest" individuals to be considered more often to reproduce children for the next generation. Each individual is assigned a probability of being selected based on its fitness value. Although individuals with higher fitness value have a higher selection probability, all individuals in the population should be given a chance to be selected. Hence, after ranking the individuals, the parents are selected randomly based on their fitness.

\section{Genetic operators}

Reproduction is carried out by applying crossover and mutation operators on the selected parents to produce offspring. The crossover and mutation operators for the proposed algorithm are discussed in what follows.
Table 7 In the interpretation of the results obtained from the proposed GA in example 1

\begin{tabular}{lllll}
\hline & L1 & L2 & L3 & L4 \\
\hline M1 & 1 & 1 & 0 & 0 \\
M2 & 0 & 0 & 0 & 1 \\
M3 & 0 & 0 & 1 & 0 \\
\hline
\end{tabular}

\section{Uniform crossover}

For every pair of randomly selected parents, a small proportion of randomly selected genes is exchanged. The crossover process is illustrated in Fig. 7. Individuals parent A and parent B produce offspring A and offspring B after applying the crossover. We define parent $\mathrm{A}$ as the direct parent of offspring $A$, and parent $B$ as the direct parent of offspring B.

\section{Mutation operator}

The conventional mutation operator randomly alters the value of the genes according to a small probability of mutation; thus, it is merely a random walk and does not guarantee a positive direction toward the optimal solution. The proposed heuristic mutation remedies this deficiency. In this scheme, an individual is randomly chosen from the population (Fig. 8).

\section{Parameters}

The parameters required to run the algorithm are population size, number of generations, number of iterations, crossover and mutation probabilities. These parameters have a crucial role in the performance of the GAs. The number of generations is a function of the size of the

Fig. 10 Convergence of $\lambda$ in example 1

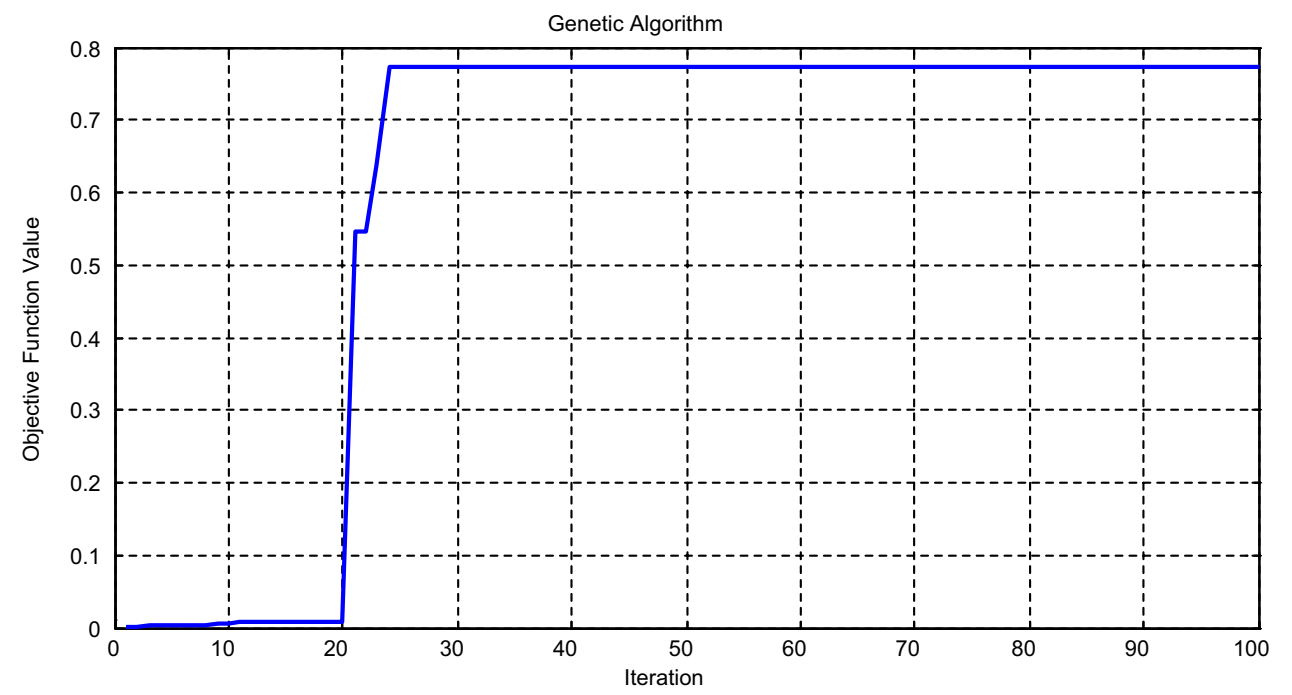


Table 8 Output information of the proposed model related to assign the machines and workers to each cell in each period using the genetic algorithm in example 1

\begin{tabular}{|c|c|c|c|c|c|c|c|c|c|c|c|c|}
\hline & \multicolumn{3}{|c|}{ Parts assigned to } & \multicolumn{3}{|c|}{ Machine in } & \multicolumn{3}{|c|}{ Worker assigned to } & \multicolumn{3}{|c|}{ Location assigned to } \\
\hline & Cell 1 & Cell 2 & Cell 3 & Cell 1 & Cell 2 & Cell 3 & Cell 1 & Cell 2 & Cell 3 & Cell 1 & Cell 2 & Cell 3 \\
\hline Period 1 & 3 & 1,2 & - & 1 & $1,2,3$ & - & 1 & 1,2 & - & 2 & $1,3,4$ & - \\
\hline Period 2 & - & - & $1,2,3$ & - & - & $1,2,3$ & - & - & 1,3 & - & - & $1,3,4$ \\
\hline
\end{tabular}

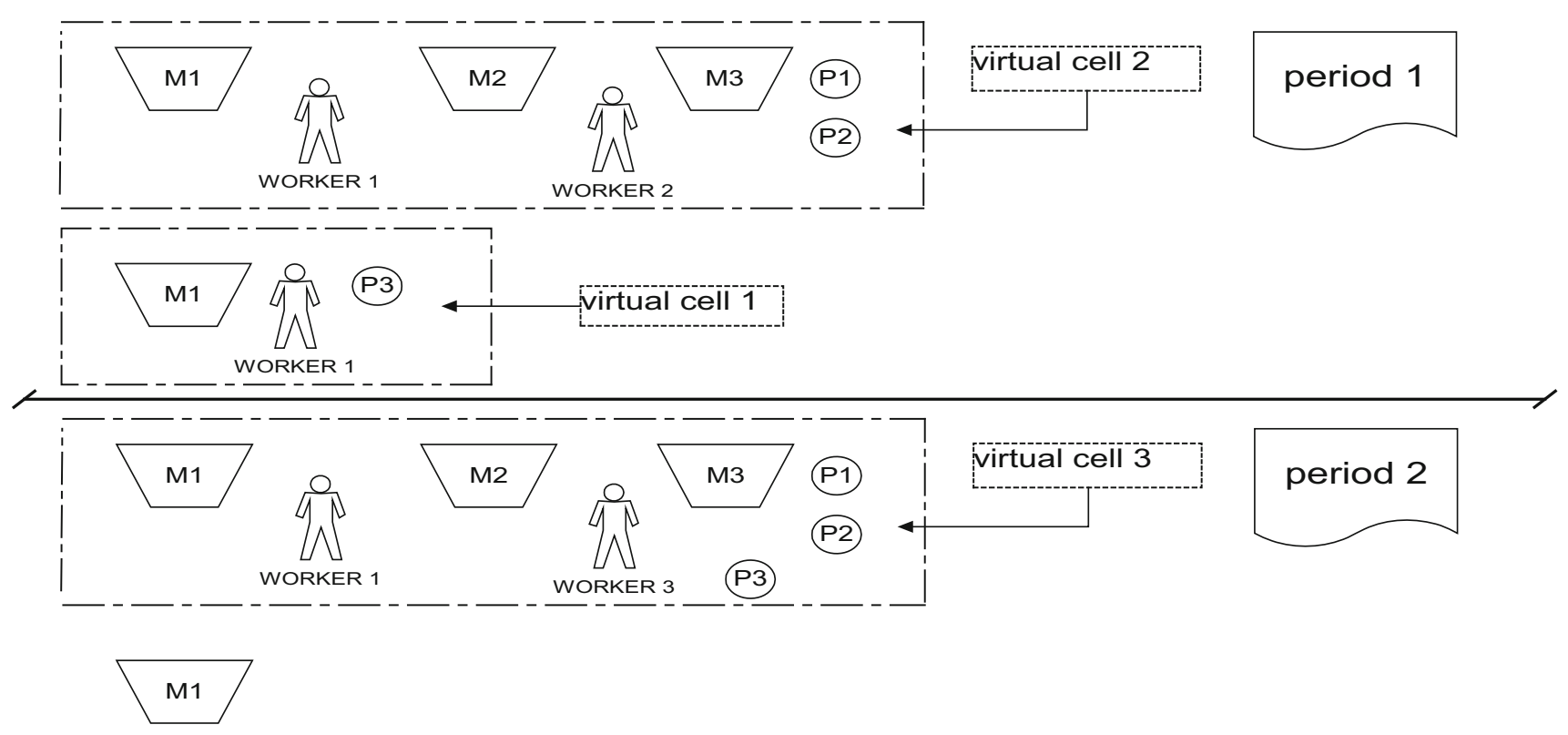

Fig. 11 Cell reconfiguration schema in each period for example 1 in the MATLAB software

problem at hand. As the solution space extends, the GA requires a larger number of generations to reach a satisfying convergence point. Population size may vary depending on the application. The number of iterations must be adjusted to allow the GA to complete the convergence process. The crossover operator has a significant effect on the performance of GA, and therefore, usually, a relatively large probability value is considered for this parameter. Mutation operator is basically used to maintain diversity in the population and is performed with a low probability.

\section{Computational results}

\section{Solving the model with LINGO software}

In this section, we present an example for which the branch and bound in the LINGO software and the genetic algorithm are utilized as solution methods. In addition, to
Table 9 GAP of between LINGO and GA

\begin{tabular}{llll}
\hline Algorithm & \multicolumn{3}{l}{ Objective function values } \\
\cline { 2 - 4 } & $\lambda$ & $Z_{1}$ & $Z_{2}$ \\
\hline LINGO & 0.812501 & 198 & 161,400 \\
The proposed GA & 0.77273 & 201 & 163,200 \\
GAP (\%) & 4.8 & 1.5 & 1.1 \\
\hline
\end{tabular}

evaluate the performance of the proposed model, a comparison of the outcomes is provided.

This example includes three cells, three parts, three machines, three workers, four locations and two periods in which all the presented hypothesis in "Problem description and formulation" are valid. Our goal is determining machine locations and cells and worker assignments.

Our data for the model include $a_{i m}$ which is a 2D variable to determine part-machine relations and is shown by the following matrix: 
Fig. 12 Convergence of $\lambda$ in example 2

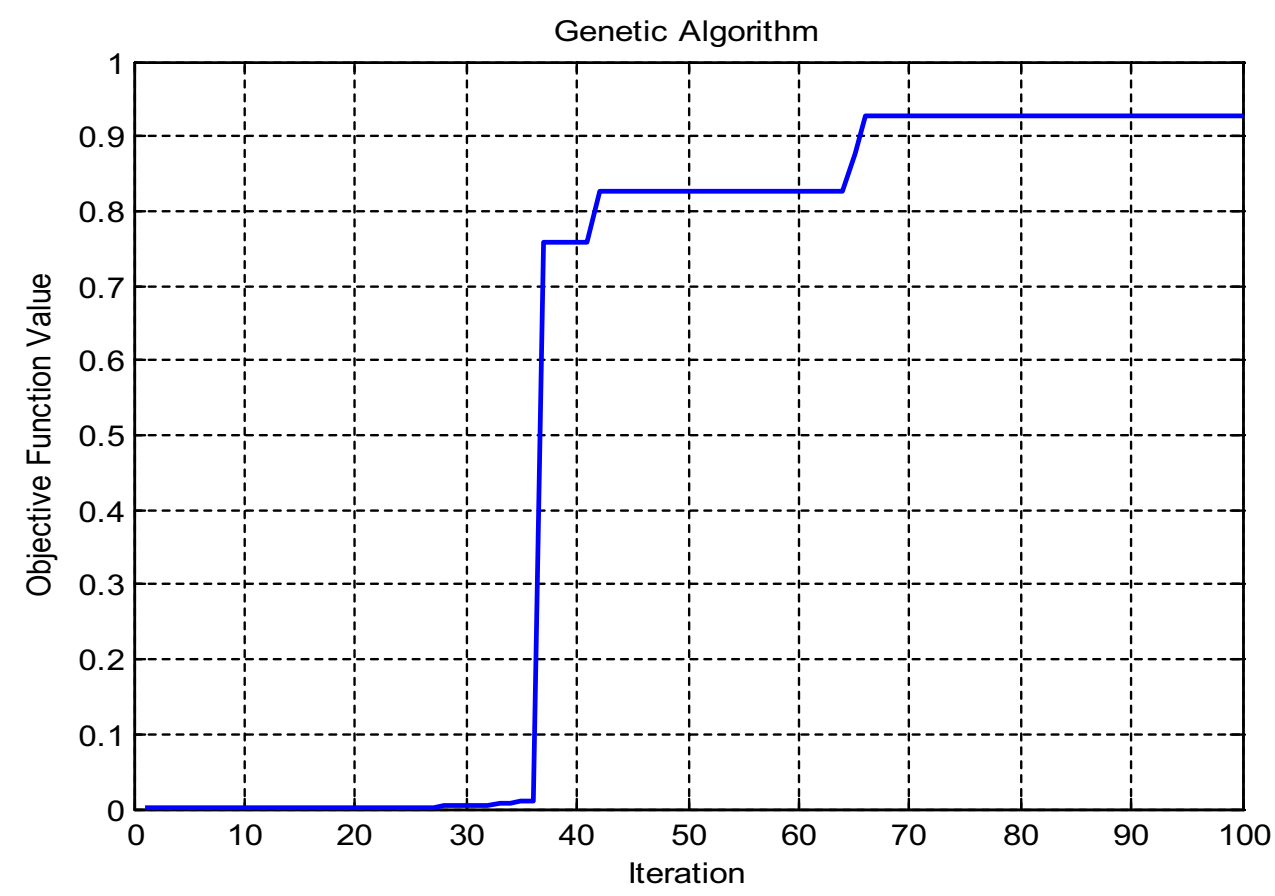

Table 10 Output information related to assign each machine to the locations used genetic algorithm in example 2

\begin{tabular}{lllllll}
\hline & L1 & L2 & L3 & L4 & L5 & L6 \\
\hline M1 & 1 & 0 & 0 & 0 & 0 & 1 \\
M2 & 0 & 1 & 0 & 0 & 1 & 0 \\
M3 & 0 & 0 & 1 & 1 & 0 & 0 \\
\hline
\end{tabular}

$a_{\text {im }}=\begin{array}{lll}1 & 0 & 1 \\ 0 & 1 & 1 \\ 1 & 0 & 0\end{array}$

Another input is $r_{m w}$ that determines the worker-machine assignments as shown as follows:

$r_{m w}=\begin{array}{lll}1 & 0 & 0 \\ 1 & 1 & 0 \\ 0 & 1 & 1\end{array}$
Table 12 Obtained values for GA variables in example 2

\begin{tabular}{llll}
\hline Variable & $\lambda$ & $Z_{1}$ & $Z_{2}$ \\
\hline Value & 0.92646 & 880 & 486,000 \\
\hline
\end{tabular}

Demand volume for each part in each period is given by:

$$
D_{i t}=\begin{array}{cc}
30 & 100 \\
70 & 80 \\
90 & 60
\end{array}
$$

The time spent for processing each part on each machine by each worker is represented by a $3 \mathrm{D}$ matrix as follows (Table 1).

The other input parameters for machines and workforces are depicted in Tables 2 and 3, respectively.

FGP model of the problem is coded and solved using the LINGO Software run on a desktop PC equipped with an Intel ${ }^{\circledR}$ Core $^{\mathrm{TM}}$ i3 @ $3200 \mathrm{GHz}$ and 4 GBs of RAM running

\begin{tabular}{|c|c|c|c|c|c|c|c|c|c|c|c|c|}
\hline & \multicolumn{3}{|c|}{ Parts assigned to } & \multicolumn{3}{|c|}{ Machine in } & \multicolumn{3}{|c|}{ Worker assigned to } & \multicolumn{3}{|c|}{ Location assigned to } \\
\hline & Cell 1 & Cell 2 & Cell 3 & Cell 1 & Cell 2 & Cell 3 & Cell 1 & Cell 2 & Cell 3 & Cell 1 & Cell 2 & Cell 3 \\
\hline Period 1 & - & 1,2 & $3,4,5$ & - & $1,2,3$ & 1,2 & - & 2,4 & 1 & - & $2,4,6$ & 1,5 \\
\hline Period 2 & $2,3,4$ & 1,5 & - & $1,2,2,3$ & 1,3 & - & 1,4 & 4 & - & $2,4,5,6$ & 1,3 & - \\
\hline Period 3 & 5 & - & $1,2,3,4$ & 1 & - & $1,2,3$ & 4 & - & 1,3 & 1 & - & $3,5,6$ \\
\hline
\end{tabular}

Table 11 Output information of the proposed model related to the machines and workers to each cell in each period using the genetic algorithm in example 2 


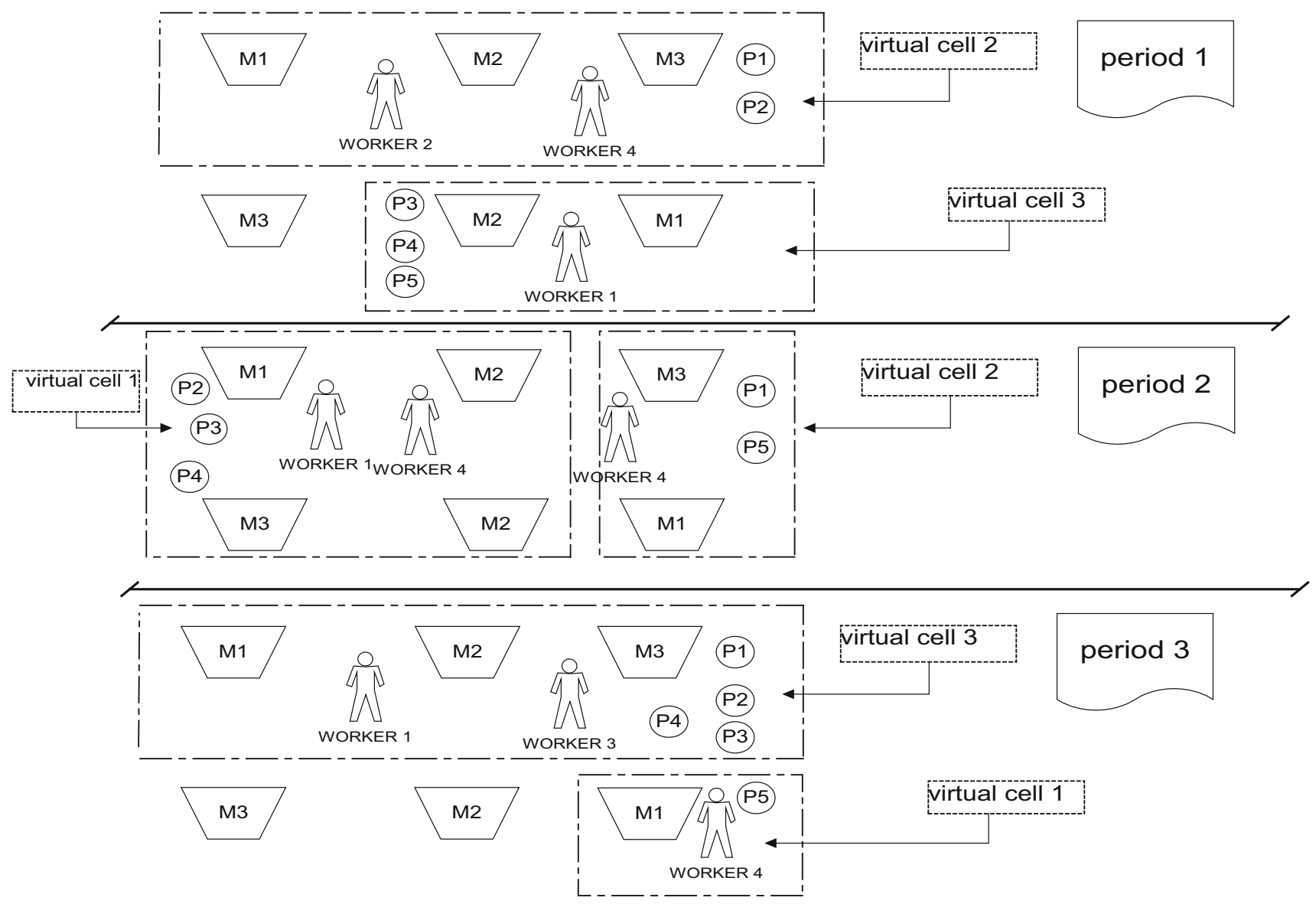

Fig. 13 Cell reconfiguration schema in each period for example 2 in the MATLAB software

Fig. 14 Convergence of $\lambda$ in example 3

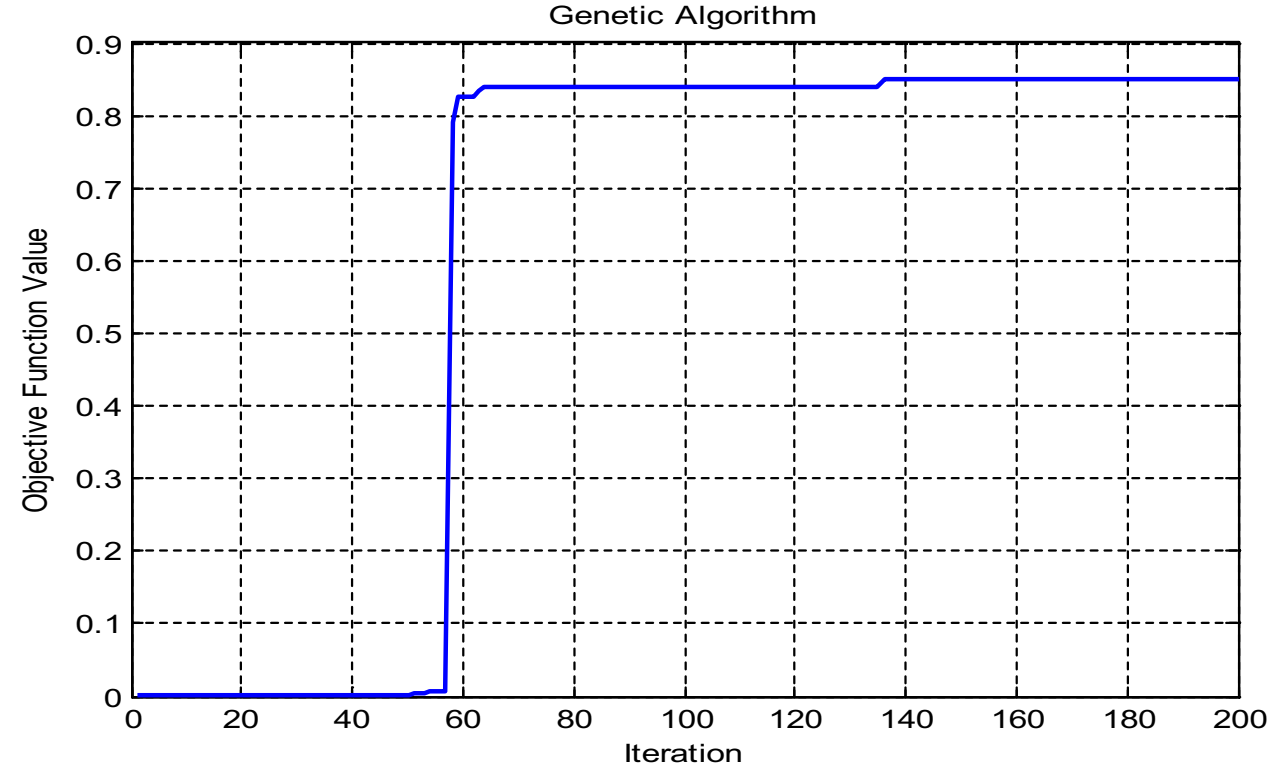




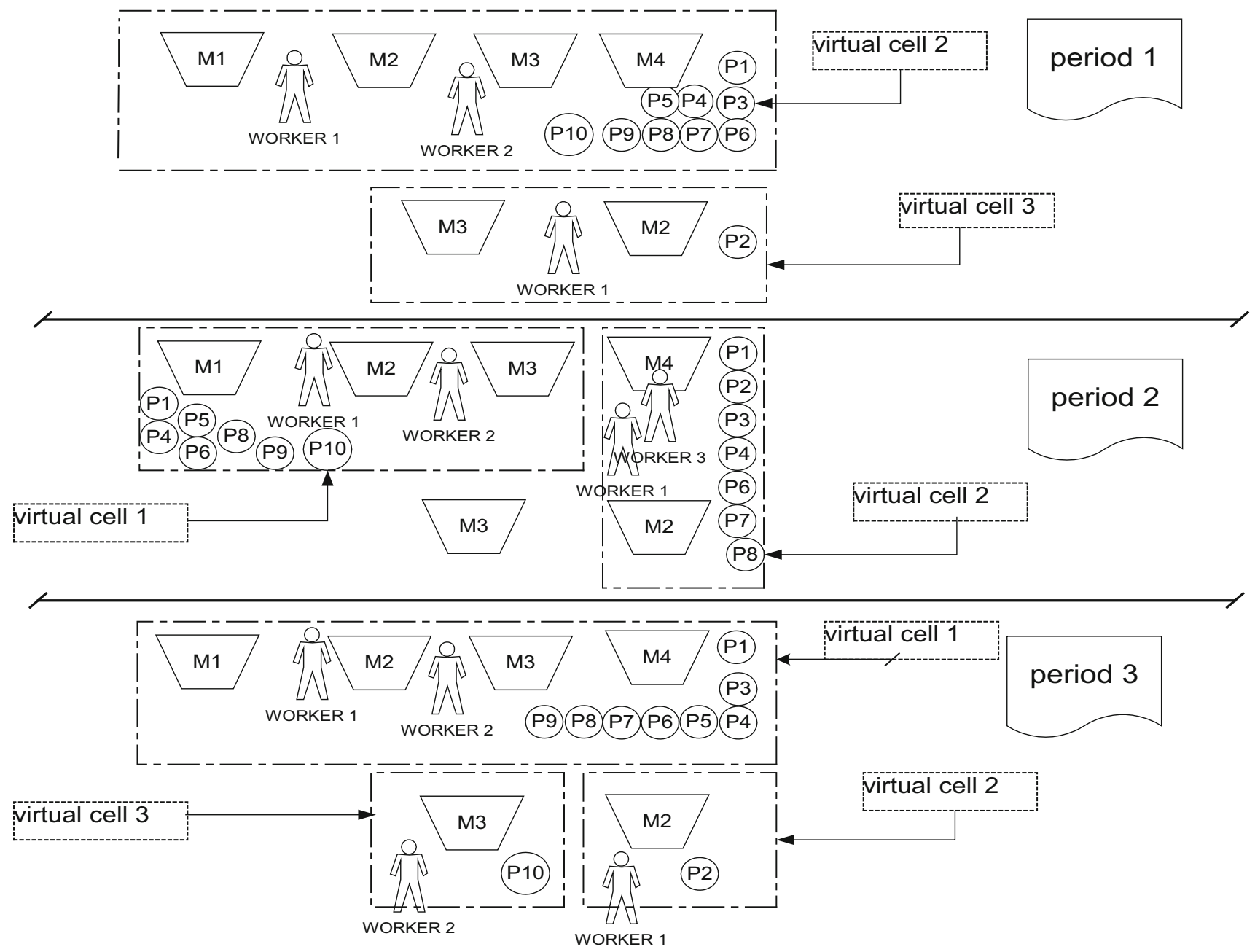

Fig. 15 Cell reconfiguration schema in each period for example 3 in the MATLAB software

Microsoft Windows ${ }^{\mathrm{TM}} 7$ Ultimate. The results were obtained after $13 \mathrm{~h}$ and $54 \mathrm{~min}$. In Table 4, parts, machines and locations assignments to cells in each period are presented. In the results, for example, in cell 3 in the first period, two machines of type 3 , one machine of type 1 and one machine of type 2 are assigned.

In Table 5, assignments of machines to locations are presented. It should be noted that the locations of machines are determined in the first period and are fixed for all periods. For instance, the machine, M2, is assigned to location 1 for all periods.

For more understanding of the results, the reconfigurations of this example are depicted in Fig. 9.

In Table 6, the obtained values for the FGP variables are presented. The optimized values of the first and second objective functions $\left(Z_{1}\right.$ and $\left.Z_{2}\right)$ are 198 and 161,400, respectively.
Table 13 Output information related to assign each machine to the locations used genetic algorithm in example 3

\begin{tabular}{lllllll}
\hline & L1 & L2 & L3 & L4 & L5 & L6 \\
\hline M1 & 1 & 0 & 0 & 0 & 0 & 0 \\
M2 & 0 & 0 & 1 & 0 & 0 & 1 \\
M3 & 0 & 0 & 0 & 1 & 1 & 0 \\
M4 & 0 & 1 & 0 & 0 & 0 & 0 \\
\hline
\end{tabular}

\section{Solving example 1 using genetic algorithm (GA)}

We coded the proposed GA solution method by MATLAB 2010 and applied the program to the same numerical example solved by the LINGO Software using the same desktop PC mentioned above and discussed in "Solving the model with LINGO software". In the results, obtained after $330 \mathrm{~s}, \lambda$ was 0.77273 for which Fig. 10 illustrates the 
Table 14 Output information of the proposed model related to assign machines and workers to each cell in each period using the genetic algorithm

\begin{tabular}{|c|c|c|c|c|c|c|c|c|c|c|c|c|}
\hline & \multicolumn{3}{|l|}{ Parts assigned to } & \multicolumn{3}{|c|}{ Machine in } & \multicolumn{3}{|c|}{ Worker assigned to } & \multicolumn{3}{|c|}{ Location assigned to } \\
\hline & Cell 1 & Cell 2 & $\begin{array}{l}\text { Cell } \\
3\end{array}$ & Cell 1 & Cell 2 & $\begin{array}{l}\text { Cell } \\
3\end{array}$ & $\begin{array}{l}\text { Cell } \\
1\end{array}$ & $\begin{array}{l}\text { Cell } \\
2\end{array}$ & $\begin{array}{l}\text { Cell } \\
3\end{array}$ & Cell 1 & Cell 2 & $\begin{array}{l}\text { Cell } \\
3\end{array}$ \\
\hline $\begin{array}{l}\text { Period } \\
1\end{array}$ & & $\begin{array}{l}1,3,4,5,6,8,7,9 \\
10\end{array}$ & 2 & & $\begin{array}{c}1,2,3 \\
4\end{array}$ & 2 & & 1,2 & 1 & & $\begin{array}{c}1,2,4, \\
6\end{array}$ & 3 \\
\hline $\begin{array}{l}\text { Period } \\
2\end{array}$ & $1,4,5,8,6,9,10$ & $1,2,3,4,6,7,8$ & & $1,2,3$ & 2,4 & & 1,2 & 1,3 & & $1,3,5$ & 2,6 & \\
\hline $\begin{array}{l}\text { Period } \\
3\end{array}$ & $\begin{array}{l}1,3,4,5,6,7,8 \\
9\end{array}$ & 2 & 10 & $\begin{array}{c}1,2,3 \\
4\end{array}$ & 2 & 3 & 1,2 & 1 & 2 & $\begin{array}{c}1,2,3, \\
4\end{array}$ & 6 & 5 \\
\hline
\end{tabular}

For more understanding, reconfigurations of this example are given in Fig. 15

Table 15 Obtained values for GA variables in example 3

\begin{tabular}{llll}
\hline Variable & $\lambda$ & $Z_{1}$ & $Z_{2}$ \\
\hline Value & 0.84897 & 1405 & 961,200 \\
\hline
\end{tabular}

convergence in 24 iterations. In this figure, vertical and horizontal axes show $\lambda$ and the number of iterations, respectively.

Therefore, the obtained values translate into the matrix depicted in Table 7.

For the parts, machines and workers, the best solution is derived from $X_{i m w k l t}$. The corresponding values are presented in Table 8 .

For more understanding of the solution, the reconfigurations of this example are given in Fig. 11.
To illustrate the performance of the proposed method, the difference percentage GAP between the proposed GA and LINGO results is calculated which is shown in Table 9.

The performance GAP shows that the proposed GA outperforms LINGO Solver with a significant GAP.

\section{Consideration of some examples with greater dimensions}

For further investiGAtion, we considered the second example with the greater dimensions. It has three periods, five types of parts, three types of machines, four types of workers, three cells and eight locations. After entering input data to the model, the results were obtained as follows:

Table 16 Comparison of the proposed GA and LINGO for small-sized examples

\begin{tabular}{|c|c|c|c|c|c|c|c|c|c|c|c|}
\hline \multirow{2}{*}{$\begin{array}{l}\text { No. of } \\
\text { example }\end{array}$} & \multicolumn{6}{|c|}{ Example size } & \multicolumn{2}{|c|}{ Objective value $(\lambda)$} & \multicolumn{2}{|c|}{ CPU time } & \multirow{2}{*}{$\begin{array}{l}\text { GAP } \\
(\%)\end{array}$} \\
\hline & $\begin{array}{l}\text { No. of part } \\
\text { types }\end{array}$ & $\begin{array}{l}\text { No. of } \\
\text { machine } \\
\text { types }\end{array}$ & $\begin{array}{l}\text { No. of } \\
\text { worker types }\end{array}$ & $\begin{array}{l}\text { No. of } \\
\text { cells }\end{array}$ & $\begin{array}{l}\text { No. of } \\
\text { locations }\end{array}$ & $\begin{array}{l}\text { No. of } \\
\text { periods }\end{array}$ & GA & LINGO & GA & LINGO & \\
\hline 1 & 2 & 2 & 2 & 2 & 3 & 2 & 0.93325 & 0.93325 & $0: 02: 55$ & 1:08:04 & 0 \\
\hline 2 & 2 & 3 & 3 & 2 & 4 & 2 & 0.83241 & 0.86241 & 0:03:46 & $6: 10: 36$ & 3 \\
\hline 3 & 3 & 3 & 3 & 3 & 4 & 2 & 0.77273 & 0.812501 & 0:05:30 & $13: 54: 00$ & 4.8 \\
\hline
\end{tabular}

Table 17 Comparison of the proposed GA and LINGO for medium-sized test examples

\begin{tabular}{|c|c|c|c|c|c|c|c|c|c|c|c|}
\hline \multirow{2}{*}{$\begin{array}{l}\text { No. of } \\
\text { example }\end{array}$} & \multicolumn{6}{|c|}{ Example size } & \multicolumn{2}{|c|}{ Objective value $(\lambda)$} & \multicolumn{2}{|c|}{ CPU time } & \multirow{2}{*}{$\begin{array}{l}\text { GAP } \\
(\%)\end{array}$} \\
\hline & $\begin{array}{l}\text { No. of part } \\
\text { types }\end{array}$ & $\begin{array}{l}\text { No. of } \\
\text { machine } \\
\text { types }\end{array}$ & $\begin{array}{l}\text { No. of } \\
\text { worker types }\end{array}$ & $\begin{array}{l}\text { No. of } \\
\text { cells }\end{array}$ & $\begin{array}{l}\text { No. of } \\
\text { locations }\end{array}$ & $\begin{array}{l}\text { No. of } \\
\text { periods }\end{array}$ & GA & $\begin{array}{l}\text { LINGO } \\
\left(Z^{\text {best }}\right)\end{array}$ & GA & $\begin{array}{l}\text { LINGO } \\
\left(Z^{\text {best }}\right)\end{array}$ & \\
\hline 1 & 4 & 3 & 3 & 2 & 6 & 2 & 0.88157 & 0.92573 & $0: 14: 35$ & 15:00:00 & 4.7 \\
\hline 2 & 5 & 3 & 4 & 3 & 8 & 3 & 0.92646 & 0.97332 & $0: 22: 07$ & 15:00:00 & 4.8 \\
\hline 3 & 6 & 4 & 4 & 3 & 8 & 3 & 0.87427 & 0.93241 & $0: 38: 24$ & 15:00:00 & 6.2 \\
\hline
\end{tabular}


Table 18 Comparison of the proposed GA and LINGO for large-sized test examples

\begin{tabular}{|c|c|c|c|c|c|c|c|c|c|c|c|}
\hline \multirow{2}{*}{$\begin{array}{l}\text { No. of } \\
\text { example }\end{array}$} & \multicolumn{6}{|c|}{ Example size } & \multicolumn{2}{|c|}{ Objective value $(\lambda)$} & \multicolumn{2}{|c|}{ CPU time } & \multirow{2}{*}{$\begin{array}{l}\text { GAP } \\
(\%)\end{array}$} \\
\hline & $\begin{array}{l}\text { No. of part } \\
\text { types }\end{array}$ & $\begin{array}{l}\text { No. of } \\
\text { machine } \\
\text { types }\end{array}$ & $\begin{array}{l}\text { No. of } \\
\text { worker types }\end{array}$ & $\begin{array}{l}\text { No. of } \\
\text { cells }\end{array}$ & $\begin{array}{l}\text { No. of } \\
\text { locations }\end{array}$ & $\begin{array}{l}\text { No. of } \\
\text { periods }\end{array}$ & GA & $\begin{array}{l}\text { LINGO } \\
\left(Z^{\text {best }}\right)\end{array}$ & GA & $\begin{array}{l}\text { LINGO } \\
\left(Z^{\text {best }}\right)\end{array}$ & \\
\hline 1 & 7 & 3 & 3 & 2 & 8 & 2 & 0.86731 & 0.82367 & $1: 43: 36$ & 15:00:00 & 5 \\
\hline 2 & 8 & 3 & 3 & 3 & 6 & 3 & 0.85294 & - & $2: 50: 14$ & - & - \\
\hline 3 & 9 & 4 & 3 & 2 & 8 & 3 & 0.8245 & - & $4: 12: 47$ & - & - \\
\hline 4 & 10 & 4 & 3 & 3 & 6 & 3 & 0.84897 & - & $5: 59: 20$ & - & - \\
\hline
\end{tabular}

Table 19 Results of the test

\begin{tabular}{llllll}
\hline Problem category & \multicolumn{2}{l}{ Objective function } & & & \multicolumn{2}{l}{ Computational time } \\
\cline { 2 - 3 } \cline { 5 - 6 } & $\mu_{\mathrm{GA}}-\mu_{\mathrm{LINGO}}$ & $P$ value & & $\mu_{\mathrm{GA}}^{\prime}-\mu_{\mathrm{LINGO}}^{\prime}$ & $P$ value \\
\hline Small & -0.0233 & 0.096 & & -0.292 & 0.099 \\
Medium & -0.04972 & 0.004 & & -0.60762 & 0.000 \\
Large & Not applicable & & & & \\
\hline
\end{tabular}

The model is solved in about $22 \mathrm{~min}(1327 \mathrm{~s})$ and achieved the solution. $\lambda$ is converged to 0.92646 and Fig. 12 depicts this convergence. The vertical axis depicts the value for $\lambda$ and the horizontal axis represents the number of iterations. After 65 iterations, $\lambda$ was converged to the aforementioned value.

The obtained values for the variables are presented as follows (Tables 10, 11, 12).

For more understanding, reconfigurations of this example are given in Fig. 13.

Example 3: In this example, we considered a problem with ten parts, three workers, four machines, three cells, three periods and six locations. We ran the model, and after $6 \mathrm{~h}(21,560 \mathrm{~s})$, the solution was found. At last, $\lambda$ value was converged to 0.84897 after 138 iterations. Figure 14 depicts these values for iteration larger than 64 . Vertical axis shows $\lambda$ value, and horizontal axis depicts the iterations.

Output values for the variables are as follows (Tables 13, 14, 15).

\section{Computational results for the proposed GA}

To show the effectiveness of the proposed GA in solving the proposed model, first three small-sized examples which can be solved optimally using LINGO are presented. The results of solving these examples using the LINGO and the proposed GA are compared in Table 16. The relative differences between the objective values, achieved by the two methods, are shown as GAP in Table 16. According to this table, in the worst case, solution GAP between the proposed GA and the global optimum found by the LINGO software is $4.8 \%$. This shows that the proposed GA is capable of obtaining the near optimal solutions in a reasonable computational time. As shown in Table 16, the LINGO software has solved the third example in a time equal to 13:54:00 which is not a reasonable computational time for solving a small-sized example.

To demonstrate the performance of the proposed GA in solving medium-sized examples, three test problems, in which LINGO fails to solve optimally, are designed and solved using the proposed GA. In a maximization problem, the LINGO software found a possible interval for optimum value of objective function $\left(Z^{*}\right)$ that is limited by the $Z^{\text {bound }}$ and $Z^{\text {best }}$ values, where $Z^{\text {best }} \leq Z^{*} \leq Z^{\text {bound }}$. $Z^{\text {best }}$ shows the best known feasible objective function value, and $Z^{\text {bound }}$ represents the upper bound of the objective function. Approaching to the current values for the best known solution and the bound, $Z^{\text {best }}$ is either the optimal solution, or very close to it. At such a point, the solver can be interrupted and report the current best solution with the aim of shortening additional computation time. Therefore, we limit runtime to $15 \mathrm{~h}$ to save computational effort and report the best solution obtained after $15 \mathrm{~h}$. To validate the results found by GA, the solutions achieved by GA for three examples are compared with $Z^{\text {best }}$ obtained by LINGO after $15 \mathrm{~h}$. These results are shown in Table 17. The GAP between the objective value of the proposed GA and $Z^{\text {best }}$ in the worst case is $6.2 \%$. This confirms that the proposed GA is able to obtain solutions to those examples effectively. In 
addition, computational time for those examples by GA is less than $40 \mathrm{~min}$ showing its superior efficiency. To evaluate the performance of the proposed GA in solving the large-sized examples, four random instances are solved by GA and LINGO, and the obtained results are shown in Table 18. LINGO solver is not capable of even finding feasible solutions for the last three test problems even after $15 \mathrm{~h}$. However, GA has solved these examples in less than $6 \mathrm{~h}$. Moreover, in the first example of Table 18 , the solution obtained by GA is better than $Z^{\text {best }}$, achieved by LINGO after $15 \mathrm{~h}$.

To further clarify the superiority of the proposed algorithm, a statistical test is conducted for each group of problems. More specifically, a paired $t$ test is utilized to compare the objective function value and computational time of the proposed algorithm and those of LINGO solver. The results of the test are presented in Table 19. In this Table, $\mu_{\mathrm{LINGO}}$ and $\mu_{\mathrm{GA}}$ are the mean objective function value for LINGO and GA, respectively, and $\mu_{\mathrm{LINGO}}^{\prime}$ and $\mu_{\mathrm{GA}}^{\prime}$ are the mean computational time for LINGO and GA, respectively.

\section{Conclusions}

In this paper, a bi-objective mathematical model for dynamic virtual cellular manufacturing system is developed which have several advantages toward the previous researches in the literature. One of the majors to another researches is introducing method to the assignment of workers alongside assignment of machines to locations in DVCMS which this mater concludes to complexity of the model. However, considering these features simultaneously causes to better planning and close to real-life situations. The most important features of this paper is as follows:

1. Developing the dimensions of cellular manufacturing problem, including machines, parts, workers and locations leading to a more realistic model.

2. Assigning workers, location to machines and parts to cells to operation processing in dynamic virtual cellular manufacturing system simultaneously.

3. Calculating the number of inter-cell transportations cost and exceptional elements in dynamic virtual cellular manufacturing system.

4. Calculating machine variable and fixed costs in each periods and also workforce hiring cost.

5. Forming virtual cells in each period.

Further researches on the proposed model may be attempted in future studies by incorporating the following issues:
- Developing a mathematical model with considering uncertainty with fuzzy parameters;

- Operation scheduling can be considered in virtual cellular manufacturing problem;

- Distances between each machine and transportation of materials can be added to the mathematical model.

Open Access This article is distributed under the terms of the Creative Commons Attribution 4.0 International License (http://crea tivecommons.org/licenses/by/4.0/), which permits unrestricted use, distribution, and reproduction in any medium, provided you give appropriate credit to the original author(s) and the source, provide a link to the Creative Commons license, and indicate if changes were made.

\section{References}

Back T, Fogel D, Michalawecz Z (1997) Handbook of evolutionary computation. Oxford University Press, Oxford

Bootaki B, Mahdavi I, Paydar MM (2014) A hybrid GA-AUGMECON method to solve a cubic cell formation problem considering different worker skills. Comput Ind Eng 75:31-40

Davis L (1991) Handbook of genetic algorithms. Van Nostrand, New York

Goldberg DE (1989) Genetic algorithms: search, optimization and machine learning. Addison-Wesley Inc, Boston

Han W, Wang F, Lv J (2014) Virtual cellular multi-period formation under the dynamic environment. IERI Procedia 10:98-104

Heragu SS (1994) Group technology and cellular manufacturing. IEEE Trans Syst Man Cybern 24(2):203-214

Liang F, Fung RYK, Jiang Z (2011) Modelling approach and behavior analysis of manufacturing resources in virtual cellular manufacturing systems using resource element concept. Int J Comput Integr Manuf 24(12):1168-1182

Mahdavi I, Paydar MM, Solimanpur M, Heidarzade A (2009) Genetic algorithm approach for solving a cell formation problem in cellular manufacturing. Expert Syst Appl 36:6598-6604

Mahdav I, Aalaei A, Paydar MM, Solimanpur M (2011) Multiobjective cell formation and production planning in dynamic virtual cellular manufacturing systems. Int $\mathbf{J}$ Prod Res 49(21):6517-6537

Mahdavi I, Paydar MM, Solimanpur M (2011) Solving a new mathematical model for cellular manufacturing system: a fuzzy goal programming approach. Iran J Oper Res 2(2):35-47

Mak KL, Peng XX, Lau TL (2007) An ant colony optimization algorithm for scheduling virtual cellular manufacturing systems. Int J Comput Integr Manuf 20(6):524-537

Narasimhan R (1980) Goal programming in a fuzzy environment. Decis Sci 11:325-326

Nikoofarid E, Aalaei A (2012) Production planning and worker assignment in a dynamic virtual cellular manufacturing system. Int J Manag Sci Eng Manag 7(2):89-95

Nomden G, Slomp J, Suresh NC (2006) Virtual manufacturing cells: a taxonomy of past research and identification of future research. Int J Flex Manuf Syst 17:71-92

Paydar MM, Saidi-Mehrabad M (2013) A hybrid genetic-variable neighborhood search algorithm for the cell formation problem based on grouping efficacy. Comput Oper Res 40:980-990

Paydar MM, Saidi-Mehrabad M (2015) Revised multi-choice goal programming for integrated supply chain design and dynamic 
virtual cell formation with fuzzy parameters. Int J Comput Integr Manuf 28(3):251-265

Rezazadeh H, Mahini R, Zarei M (2011) Solving a dynamic virtual cell formation problem by linear programming embedded particle swarm optimization algorithm. Appl Soft Comput 11:3160-3169

Rheault M, Drolet J, Abdulnour G (1995) Physically reconfigurable virtual cells: a dynamic model for a highly dynamic environment. Comput Ind Eng 29(1-4):221-225

Slomp J, Chowdary BV, Suresh NC (2005) Design of virtual manufacturing cells: a mathematical programming approach. Robot Comput Integr Manuf 21(3):273-288
Thomalla CS (2000) Formation of virtual cells in manufacturing systems. In: Proceedings of group technology/cellular manufacturing world symposium, San Juan, pp 13-16

Wemmerlov U, Hyer NL (1989) Cellular manufacturing in the US industry: a survey of users. Int J Prod Res 27(9):1511-1530

Yang T, Ignizio JP, Kism HJ (1991) Fuzzy programming with nonlinear membership functions: piecewise linear approximation. Fuzzy Sets Syst 11:39-53

Zimmermann HJ (1978) Fuzzy programming and linear programming with several objective functions. Fuzzy Sets Syst 1:45-55 